\title{
Military assistance to the civil authority: medical liaison with the Manchester clinicians after the Arena bombing
}

\author{
Douglas M Bowley, ${ }^{1}$ N Davis, ${ }^{2}$ M Ballard, ${ }^{3}$ L Orr, $^{4}$ J Eddleston ${ }^{5}$
}

\begin{abstract}
${ }^{1}$ General Surgery, Royal Centre for Defence Medicine, Birmingham, UK ${ }^{2}$ Paediatric Orthopaedic Surgery, Royal Manchester Children's Hospital, Manchester, UK ${ }^{3}$ Radiology, Royal Centre for Defence Medicine, Birmingham,

${ }^{4}$ Otorhinolaryngology, Royal Centre for Defence Medicine, Birmingham, UK

${ }^{5}$ Intensive Care Medicine and Anaesthesia in Manchester Royal Infirmary, Clinical Head of the Clinical and Scientific Services Division within the Trust and Deputy Medical Director, Manchester, UK
\end{abstract}

\section{Correspondence to}

Douglas M Bowley, Consultant general surgeon, Royal Centre for Defence Medicine, Birmingham B15 2TG, UK; doug.bowley@heartofengland. nhs.uk

Received 13 March 2018 Revised 28 June 2018 Accepted 28 June 2018

\section{Check for updates}

(c) Author(s) (or their employer(s)) 2018. No commercial re-use. See rights and permissions. Published by BMJ.

To cite: Bowley DM, Davis $N_{t}$ Ballard $\mathrm{M}$, et al.

J R Army Med Corps Epub ahead of print: [please

include Day Month Year].

doi:10.1136/

jramc-2018-000944

\section{ABSTRACT}

UK Defence Medical Services' personnel have experienced an intense exposure to patients injured during war over the last decade and a half. As some bitter lessons of war surgery were relearned and innovative practices introduced, outcomes for patients impr oved consistently as experience accumulated. The repository of many of the enduring lessons learnt at the Role 4 echelon of care remain at the Queen Elizabeth Hospital Birmingham (QEHB), with the National Health Service and Defence Medical Services personnel who treated the returning casualties. On 22 May 2017, a terrorist detonated an improvised explosive device at the Manchester Arena, killing 22 and wounding 159 people. In the aftermath of the event, QEHB was requested to provide support to the Manchester clinicians and teleconferencing and then two clinical visits were arranged. This short report describes the nature of the visits, outlines the principles of Military Aid to the Civil Authority and looks to the future role of the Defence Medical Services in planning and response to UK terrorism events.

\section{INTRODUCTION}

In response to concerns about the response of UK authorities to certain crises (such as the Foot and Mouth outbreak in 2001), the Civil Contingencies Act (CCA) was signed into law in 2004. It defines the framework for emergency planning and response to local, regional and national emergency. Emergency has a rather broad definition, including 'war or attack by a foreign power, terrorism or other event that threatens security or an event that threatens serious damage to human welfare or to the environment'. ${ }^{1}$ The CCA defines the obligations of various UK organisations to prepare for emergencies and provides for additional powers for government to use in the event of a large-scale emergency. Local emergency services will, of course, provide the first response to any emergency. Coordination of both resilience planning and crisis management is facilitated by the Civil Contingencies Secretariat (part of the Cabinet Office). Immediate response will be by Category 1 responders (typically 'blue light services') supported by Category 2 responders, who are typically utilities and transportation providers. When necessary, Government departments or civil authorities may request military assistance from the Ministry of Defence (MOD). The National Security Strategy and Strategic Defence and Security Review $2015^{2}$ provides for Military Aid to the Civil Authorities (MACA). It is defined as provision of 'assistance

\section{Key messages}

Clinicians within the Defence Medical Services (DMS) have experienced an intense exposure to patients injured during war over the last decade and a half.

- This knowledge enables the DMS to provide Military Assistance to the Civil Authority (MACA) to our colleagues in the National Health Service (NHS) in times of need.

- On 22 May 2017, a terrorist detonated an improvised explosive device at the Manchester Arena, killing 22 and wounding 159 people.

- The DMS was asked following this event to provide support to the Manchester NHS clinicians.

- This paper looks to the future role of the DMS in MACA planning and response to UK terrorism events.

provided by the armed forces to other government departments for urgent work of national importance, responding to emergencies or in maintaining supplies and essential services'.

Defence has seven tasks ${ }^{2}$ :

1. Defending the UK and its overseas territories.

2. Provision of strategic intelligence.

3. Provision of deterrence.

4. Support of civil emergency organisations in time of crisis.

5. Defence of national interest (by projecting power).

6. Provision of a defence contribution to UK influence.

7. Provision of security for stabilisation.

The formal MACA framework ${ }^{3}$ enables MOD to plan for and deliver assistance in line with the Defence Plan in two ways:

1. By providing niche capabilities, which MOD needs for its own purposes and which government does not wish or need to generate independently, for example, Explosive Ordnance Disposal (EOD).

2. By standing ready to support the civil authorities when their capacity is overwhelmed. The armed forces provide this support from spare capacity, so it is subject to the availability of resources, without affecting core MOD objectives.

Examples of MACA include: Operation BRIDLED, military support to the response to the Didcot Power Station collapse in February 2016 ${ }^{4}$; Operation 
SHAKU, military support to floods in the north of England in 2015-2016 ; Operation PITCHPOLE, flood response in the Thames Valley in $2014^{6}$ and Operation FRESCO, the military support during the firefighter industrial action of 2002-2003. ${ }^{7}$

An example of MACA in the context of terrorist threats to the UK is Operation TEMPERER. Planning for Operation TEMPERER was initiated in January 2015, in response to the series of attacks in Paris that started with the attack on the Charlie Hebdo offices on 7 January 2015. Designed to release over 5000 tri-service military personnel to augment police officers engaged in protective security duties, TEMPERER was planned to be kept secret; however, it was accidentally disclosed in $2015 .^{8}$ TEMPERER was put into effect for the first time on 23 May 2017 following the Manchester Arena bombing. ${ }^{9}$ As defined by the CAA, the initial response to the Manchester Arena bombing on 22 May 2017 was planned and delivered by Category 1 responders (Local authorities, Police forces, Ambulance services and National Health Service (NHS) hospital trusts).

In the aftermath of the Arena bombing, Queen Elizabeth Hospital Birmingham (QEHB) was requested to send a clinical delegation to Manchester to visit the major hospitals that had taken casualties. This was supported by members of the Royal Centre for Defence Medicine (RCDM), the military unit that is co-located with QEHB. RCDM has been the primary receiving facility for UK service personnel evacuated from overseas since its formation in 2001. This QEHB/RCDMmultidisciplinary specialty team took part in teleconferencing in the immediate aftermath of the Manchester Arena bombing of 22 May 2017. The team was subsequently invited to visit the Combined Manchester Hospitals on Day 3 and Day 10 postincident. The purpose of the conferencing and clinical visits were to deliver assurance, peer support and to facilitate ongoing peer review.

A QEHB/RCDMdelegation visited Manchester (MCR) Hospitals on 25 May and 1 June 2017. The delegates comprised clinicians from: Anaesthesia, General Surgery, Intensive Care Medicine, Neurology/Rehabilitation, Plastic/Reconstructive Surgery and Trauma Orthopaedics. At each site, the format of the visit was for the delegation to attend the daily major trauma hand-over meetings (when possible) or to attend a similar meeting convened for the purpose and then to undertake focused bedside visits to discuss individual clinical challenges. In addition to the clinical delegation, a DMS radiology team delivered expertise not available in the NHS to support forensic analysis of deceased persons and a Ear, Nose and tTroat team provided specialist advice. The QEHB/RCDMdelegation were able to provide subject matter expertise to MCR clinicians, acted as a sounding board, were able to provide assurance about the high quality of the care provided and offered ongoing support in capture and dissemination of learning.

\section{PATTERN OF INJURY}

Throughout the UK military medical experience in Iraq and Afghanistan (Ops TELIC and HERRICK), experience was gained in treating patients who had been exposed to ballistic trauma. In particular, this included explosive injury (often concealed Improvised Explosive Devices, IEDs) or high energy transfer gunshot injury. UK service personnel universally wore body armour and helmets, and therefore extremity and limb injuries predominated in survivors. Amputation was a common sequela and the most severely injured often had bilateral high lower limb amputation, open pelvic fracture and other injuries. Service personnel were exposed to blast on foot patrol (dismounted) or within vehicles; IED were commonly buried underground and typically had low metal content. ${ }^{10}$ The victims of the Manchester Arena attack were subjected to an open air blast of a device carried by a suicide bomber and the device had been surrounded by metal objects that were energised by the blast and became projectiles. This resulted in penetrating injury (secondary blast). With high lethality of those close to the epicentre of the explosion, there were few survivors with obvious primary blast injury. Nevertheless, in one patient, pulmonary thrombosis was identified on the admission CT scan. The military experience enabled reassurance of the civilian clinicians that this was in all likelihood acute peritraumatic pulmonary thrombus (APPT). This is a phenomenon that was identified in nearly $10 \%$ of major trauma admissions in the Afghanistan war hospital. ${ }^{11}$ APPT is generally considered to be incidental and unlikely to require intervention such as anticoagulation or vena caval filter devices.

\section{SHAPING THE WOUND}

The principles of war surgery relearned in the wars in Iraq and Afghanistan have been: arrest of haemorrhage, thorough wound debridement and lavage, temporary stabilisation of fractures and a staged approach to first 'shape' wounds and subsequently reconstruct them. ${ }^{12}$ A key principle is that wounds can vary widely and that an arbitrary distinction into low energy wounds (with little contamination-that can be closed) and high energy wounds (with significant contamination-that must be left open) can be unhelpful, as the different wound types can coexist. Debridement can be:

- Marginal: in which all the necrotic tissue is removed but injured and potentially viable tissue is retained.

- Complete: removal of both necrosed and marginal tissue.

- Radical: which includes normal tissue within the field of excision.

Recent military experience is that meticulous repeated marginal debridement of military wounds preserves as much tissue as possible and maximises functional outcomes. 'Complete' debridement is hard to judge and radical debridement involves the removal of tissue which would otherwise survive. Military protocols now recommend repeated debridement every 48-72 hour until no further sign of necrosis or infection has occurred. Military protocol is to recommend delaying softtissue reconstruction until the wounds are macroscopically clean and remain so on two successive debridements and the patient requiring minimal physiological support. This protocol contrasts with the International Red Cross (IRC) guidelines that recommend an initial (radical) debridement followed by application of gauze dressings, which are then left undisturbed until a delayed primary closure is performed at 4-7 days: 'once the exudative phase of trauma inflammation has subsided and the proliferative phase begun'. 13

A further recent development in military surgery has been the concept of damage control operations particularly for laparotomy ${ }^{14}$ but also for other anatomical regions, such as the chest and head, and the use of vascular shunts for vascular injury. ${ }^{15-17}$ The QEHB/RCDM delegation discussed our experience with the Manchester clinicians and we were able to compare and contrast the clinical challenges faced. The stance of the QEHB/RCDM delegation was that of 'humble learners' and we acknowledged that not only were the patterns of wounding different from 'Afghan standard', but that considerable, high level expertise was widespread among the Manchester clinicians. The largely concrete concourse of the Arena is obviously different to the 'Green Zone' of Helmand and the nature of the device (man-portable IED packed with metallic objects) meant that 
survivors sustained little primary blast injury, but had extensive ballistic injury from the metal nuts and cable packed around the device. The nature of the event targeted by the perpetrator meant that significant numbers of survivors were children and young people.

\section{THE IMPACT OF TERRORISM ON CHILDREN}

In a review of mass casualty incidents in Israel, injuries among teenagers (ages 10-17 years) were twice as likely as those of younger children (ages $0-9$ years), (67\% and 33\%, respectively $(\mathrm{p}<0.05))$. The head, face and neck (HFN) region was the most common to be injured (67\%), followed by upper and lower extremities $(62 \%){ }^{18} \mathrm{~A}$ review of paediatric blast casualties at Camp Bastion Role 3 Medical Facility confirmed that children are more likely to sustain severe HFN injuries than adults. $^{19}$

\section{LESSONS LEARNT}

There was recognition that the Manchester major trauma network had performed exceptionally well and that individual clinical interactions were consistently undertaken to a very high standard. Operationally, the Greater Manchester dispersal plan worked very well; however, there were certain factors that will require further work to be fully incorporated into future plans. The incident produced a much longer clinical 'tail' than had been anticipated; it took 2 months for the operational performance of the most impacted hospitals in Manchester to return to 'business as usual'. Evaluation of the Greater Manchester response to the Arena bombing also highlighted a potential additional role for Local Emergency Hospitals (LEH), beyond caring for patients with 'low-acuity' traumatic injuries. Acute medical patients could be redirected to LEHs in the immediate aftermath of a mass casualty incident, thereby clearing pressure in the Major Trauma Centres. To accept the number of acute medical admissions will require a structured response; however, staff at the LEHs felt that, in this way, they could offer a further valuable part of the response to any such incident in the future. The issue of consent for sharing clinical information was also highlighted. This was not so much between NHS organisations or clinicians, but information governance was a concern when there were requests for clinical information between NHS and non-NHS organisations. This included social care or third parties such as the trustees or the 'fourth estate'.

There was recognition that the MCR pattern of injury differed from the typical injuries experienced by UK servicemen after IED strike in Afghanistan and that surgical care was excellent across the board. Nevertheless, there were minor inconsistencies in surgical protocols (some primary closure of a few minor ballistic wounds occurred). The MCR clinicians identified a high yield of significant nerve and tendon injuries on secondary and tertiary surveys. The invited delegation felt that some overenthusiastic relooking of wounds and surgery to retrieve missile fragments had occurred. There was also some enthusiasm for 'hyper acute' complex reconstruction and this was counselled against. There was a recognition that pneumoperitoneum can occur after blast injury without visceral injury ${ }^{20}$ and negative laparotomy can occur (but also that negative laparotomy is a 'lesser evil' that a missed injury). There was a requirement identified for clear recommendations for management of risk of blood-borne viruses and policies concerning management of noise induced hearing loss and antimicrobial prophylaxis after blast injury. ${ }^{21-23}$ In addition to these clinical factors, it was realised that there was a requirement for enhanced welfare support for patients' relatives and for members of staff, both those who had directly treated patients and those who had not.

\section{DEFENCE OTOLOGY CONTRIBUTION}

Properties of the ear that allow it to act as a biological pressure transducer make it inherently susceptible to damage as a result of blast. Disruption of the soft tissues within the ear canal, the ear drum and ossicular chain can be managed in relatively 'slow time'. Recent evidence, however, supports interventions capable of rescuing some hearing loss associated with sensorineural damage. The immediate otological challenge of the Arena bombing concerned the possible practicalities of determining the presence and extent of any hearing loss in a potentially large number of people including many children. There was also the possibility of a cohort of patients presenting late to their general practitioner (GP) with no injury other than hearing loss, and the need for a proportionate response. A military-led team at QEHB undertook a rapid literature review to develop protocols for adults and children forthe management of hearing loss in a mass casualty situation and these were provided to the Manchester team. Flow diagrams included detailed advice on the medical options available, the role of intratympanic steroids and special considerations as to the use of high dose steroids particularly in multiply injured patients and in children. The protocols were designed to be used by GPs to help triage those with possible acoustic injury and also to inform definitive assessment and treatment of both forms of hearing loss in a secondary care setting. ${ }^{22}$

\section{DEFENCE IMAGING CONTRIBUTION}

CT was introduced to forensic sciences in 1977 by Wüllenweber et al to aid in the assessment of patients who had died after gunshot injuries. ${ }^{24}$ Experience with forensic CT in the understanding of unnatural death was first used in the UK in Manchester in the 1990s in response to local religiously motivated objection to autopsy. ${ }^{25}$ The UK Defence Medical Services have accumulated significant experience in forensic radiology after blast injury and a Defence imaging team consisting of three radiologists and four radiographers was tasked to support the forensic process following the MCR bombing. The team utilised cross-sectional imaging with CT, standard radiographic imaging with small portable X-ray machines and ultrasound. While the overarching cause of death was largely understood for the Arena victims, forensic radiological analysis supported the pathologist in resolving the de facto cause of death and served to support the forensic investigation. In the absence of imaging, the pathologist must serially and methodically explore relevant body cavities and fascial compartments- a process which may take several hours. In a mass casualty event such as the MCR bombing, with 22 victims, a conventional forensic process could have lasted several weeks. In addition to speeding up the forensic examination, radiology allows the pathologist to minimise the otherwise necessary dissection of the deceased; a fact that can provide some small comfort to the relatives. Forensic imaging started with a CT scan of the victim and subsequent body mapping of fragments with a detailed assessment of injuries and wounding tracts. Prior to conventional autopsy, a case conference allowed detailed discussion and direction so the pathologist knew where to look when the autopsy was undertaken. During the autopsy, radiographers with portable X-ray equipment were able to correlate the CT body map to the victim and further refine the forensic process. Ultrasound was used to further facilitate localisation within organs. 


\section{CONCLUSIONS}

Debriefing and sharing information about mass casualty events are critical so that lessons learnt can be rapidly incorporated into local and national future plans. ${ }^{26}$ Feedback from the 'frontline' MCR clinicians was that QEHB/RCDM visits had been extremely helpful, providing both support for urgent issues and longer term reassurance and the predominant sentiment was that this sort of engagement should become a standard operating procedure for future such events. Multiple representatives stated that the first visit by the QEHB/RCDM delegation should have occurred earlier (ie, on Day 1 rather than Day 3). A second visit, with involvement of rehabilitation specialist, was considered appropriate around Day 10.

The post-Arena feedback from forensic pathologists and the Coroner in MCR confirmed that this collaborative and multidisciplinary approach to forensic autopsy not only increased accuracy and specificity of forensic recovery but also enabled a more rapid forensic understanding of the major incident. It also supported the authorities' compassionate interaction with families of the deceased.

Military Aid to the Civil Authority can occur in different ways, ranging from mountain rescue, soldiers filling sandbags or guarding civil infrastructure. The repository of expertise in the management of blast injury at QEHB/RCDM enabled projection of healthcare support and engagement in response to an incident on home soil. Some of the clinical lessons and personal coping strategies learnt from battlefield medicine can be used to encourage and sustain NHS clinicians as they work so hard to save lives and improve long-term functional outcomes for patients. The sharing of personal experience may also make a contribution to morale of NHS workers, extending resilience and their ability to cope with the impact of events.

Contributors DMB was responsible for the planning. All authors contributed to the conducting and reporting.

Funding The authors have not declared a specific grant for this research from any funding agency in the public, commercial or not-for-profit sectors.

Competing interests None declared.

Patient consent Not required.

Provenance and peer review Commissioned; internally peer reviewed.

\section{REFERENCES}

1 Civil Contingencies Act. 2004 https://www.legislation.gov.uk/ukpga/2004/36/ contents (accessed 01 Mar 2018).

2 National Security Strategy and Strategic Defence and Security Review 2015. https:// www.gov.uk/government/publications/national-security-strategy-and-strategicdefence-and-security-review-2015 (accessed 01 Mar 2018).

3 Joint Doctrine Publication 02: UK Operations: the Defence Contribution to Resilience and Security. https://www.gov.uk/government/publications/operations-in-the-uk-ajoint-doctrine-publication (accessed 01 Mar 2018).
4 Op BRIDLED. https://www.armyengineer.co.uk/2016/11/24/gillingham-fc-pre-seasonpti/ (accessed 01 Mar 2018).

5 Op SHAKU. https://modmedia.blog.gov.uk/2016/01/09/reservists-from-the-the-dukeof-lancasters-regiment-support-the-civil-authorities-during-the-floods/ (accessed 01 Mar 2018).

6 Op PITCHPOLE. https://www.royalnavy.mod.uk/news-and-latest-activity/operations/ uk-home-waters/op-pitchpole (accessed 01 Mar 2018.).

7 Op FRESCO. https://www.telegraph.co.uk/news/uknews/1403508/30000-soldiers-onalert-to-step-in-for-striking-firemen.html (accessed 01 Mar 2018.).

8 Op TEMPERER. http://www.dailymail.co.uk/news/article-3174590/Secret-plan-5-000heavily-armed-troops-streets-Britain-fight-jihadis-event-terror-attack.html (accessed 01 Mar 2018.).

9 Op TEMPERER. https://ukdefencejournal.org.uk/operation-temperer-started-heresneed-know/ (accessed 01 Mar 2018.).

10 Oh JS, Tubb CC, Poepping TP, et al. Dismounted blast injuries in patients treated at a role 3 military Hospital in Afghanistan: patterns of injury and mortality. Mil Med 2016;181:1069-74.

11 Lundy JB, Oh JS, Chung KK, et al. Frequency and relevance of acute peritraumatic pulmonary thrombus diagnosed by computed tomographic imaging in combat casualties. J Trauma Acute Care Surg 2013;75(2 Suppl 2):S215-S220.

12 Evriviades D, Jeffery $S$, Cubison T, et al. Shaping the military wound: issues surrounding the reconstruction of injured servicemen at the Royal Centre for Defence Medicine. Philos Trans R Soc Lond B Biol Sci 2011;366:219-30.

13 Surgical Management of War Wounds. In: Giannou C, Baldan M, Technique of wound debridement war surgery: working with limited resources in armed conflict and other situations of violence Vol I. Chapter 10. 216-222. Geneva: International Committee of the Red Cross, 2013.

14 Smith IM, Beech ZK, Lundy JB, et al. A prospective observational study of abdominal injury management in contemporary military operations: damage control laparotomy is associated with high survivability and low rates of fecal diversion. Ann Surg 2015;261:765-73.

15 Poon $\mathrm{H}$, Morrison JJ, Apodaca AN, et al. The UK military experience of thoracic injury in the wars in Iraq and Afghanistan. Injury 2013;44:1165-70.

16 Teff RJ. Use of neurosurgical decision-making and damage-control neurosurgery courses in the Iraq and Afghanistan conflicts: a surgeon's experience. Neurosurg Focus 2010;28:E9.

17 Rasmussen TE, Clouse WD, Jenkins DH, et al. The use of temporary vascular shunts as a damage control adjunct in the management of wartime vascular injury. J Trauma 2006:61:8-15. discussion 12-5.

18 Waisman Y, Goldman S, Poznanski O, et al. [Pediatric injuries from mass casualty events in Israel: a ten-year summary]. Harefuah 2010;149:482-6.

19 Thompson DC, Crooks RJ, Clasper JC, et al. The pattern of paediatric blast injury in Afghanistan. J R Army Med Corps 2017:jramc-2017-000795.

20 Bowley DM, Gillingham S, Mercer S, et al. Pneumoperitoneum without visceral trauma: an under-recognised phenomenon after blast injury? J R Army Med Corps 2013:159:312-3.

21 Bloodborne viruses: managing risk in bomb blast victims. 2017 https://www.gov.uk/ government/publications/bloodborne-virus-managing-risk-in-bomb-blast-victims.

22 Muzaffar SJ, Orr L, Rickard RF, et al. Mitigating noise-induced hearing loss after blast injury. Trauma. In Press.

23 Antimicrobial Prophylaxis Guidance for Bomb Blast Victims. 2017. https://www.gov. uk/government/uploads/system/uploads/attachment_data/file/616113/Antimicrobial_ prophylaxis_guidance_for_bomb_blast_victims.pdf (accessed 01 Mar 2018).

24 Wüllenweber R, Schneider V, Grumme T. Acomputer-tomographical examination of cranial bullet wounds (author'stransl). [Articlein German] Z Rechtsmed 1977;80:227-46

25 Roberts IS, Benamore RE, Benbow EW, et al. Post-mortem imaging as an alternative to autopsy in the diagnosis of adult deaths: a validation study. Lancet 2012:379:136-42.

26 Moran CG, Webb C, Brohi K, et al. Lessons in planning from mass casualty events in UK. BMJ 2017:359:j4765. 